\title{
US FDA Vaccines Technical Specification
} Guidance v1.0

National Cancer Institute

\section{Source}

National Cancer Institute. US FDA Vaccines Technical Specification Guidance v1.0. NCI

Thesaurus. Code C161474.

The 1.0 version of the FDA Vaccines Technical Specifications Guidance. 